\title{
Sox10 Cooperates with the Mediator Subunit 12 during Terminal Differentiation of Myelinating Glia
}

\author{
Michael R. Vogl, ${ }^{1 \star}$ Simone Reiprich, ${ }^{1 \star}$ Melanie Küspert, ${ }^{1}$ Thomas Kosian, ${ }^{1}$ Heinrich Schrewe, ${ }^{2}$ Klaus-Armin Nave, ${ }^{3}$ \\ and Michael Wegner ${ }^{1}$ \\ ${ }^{1}$ Institut für Biochemie, Emil-Fischer-Zentrum, Universität Erlangen-Nürnberg, D-91054 Erlangen, Germany, ${ }^{2}$ Department of Developmental Genetics, \\ Max-Planck Institute for Molecular Genetics, D-14195 Berlin, Germany, and ${ }^{3}$ Department of Neurogenetics, Max Planck Institute of Experimental \\ Medicine, D-37075 Goettingen, Germany
}

Several transcription factors are essential for terminal differentiation of myelinating glia, among them the high-mobility-group-domaincontaining protein Sox10. To better understand how these factors exert their effects and shape glial expression programs, we identified and characterized a physical and functional link between Sox 10 and the Med12 subunit of the Mediator complex that serves as a conserved multiprotein interphase between transcription factors and the general transcription machinery. We found that Sox10 bound with two of its conserved domains to the C-terminal region of Med12 and its close relative, Med12-like. In contrast to Med12-like, substantial amounts of Med12 were detected in both Schwann cells and oligodendrocytes. Its conditional glia-specific deletion in mice led to terminal differentiation defects that were highly reminiscent of those obtained after Sox10 deletion. In support of a functional cooperation, both proteins were jointly required for Krox20 induction and were physically associated with the critical regulatory region of the Krox 20 gene in myelinating Schwann cells. We conclude that Sox10 functions during terminal differentiation of myelinating glia, at least in part by Med12-dependent recruitment of the Mediator complex.

\section{Introduction}

Rapid saltatory conduction is essential for proper functioning of the vertebrate nervous system and depends on myelination of axons by specialized glia: Schwann cells in the peripheral nervous system (PNS) and oligodendrocytes in the CNS. Myelination is a tightly controlled process that requires reciprocal signaling between axon and glial cell; on the glial side, it leads first to induction and later to maintenance of a special gene expression program.

Several transcription factors orchestrate the myelination program in Schwann cells and oligodendrocytes; these include Nfatc3/c4, the POU homeodomain transcription factor Oct6, and the zinc finger transcription factor Krox20 (also referred to as Egr2) in Schwann cells (for review, see Svaren and Meijer, 2008), whereas the closely related bHLH proteins Olig1 and Olig2, the homeodomain protein $\mathrm{Nkx} 2.2$, and the Ndt80-domaincontaining Mrf regulate myelination in oligodendrocytes (for review, see Li et al., 2009). Also involved in both cell types is the high-mobility-group (HMG)-domain-containing transcription factor Sox10 (Stolt et al., 2002; Finzsch et al., 2010; Fröb et al.,

Received Nov. 6, 2012; revised Feb. 15, 2013; accepted March 12, 2013.

Author contributions: M.W. designed research; M.R.V., S.R., M.K., and T.K. performed research; H.S. and K.-A.N. contributed unpublished reagents/analytic tools; M.R.V., S.R., M.K., T.K., and M.W. analyzed data; M.W. wrote the paper.

This work was supported by the Deutsche Forschungsgemeinschaft (Grant \#We1326/8-2 to M.W.). We thank Dr. T. Boyer for advice.

${ }^{*}$ M.R.V. and S.R. contributed equally to this work.

Correspondence should be addressed to Michael Wegner, Institut für Biochemie, Emil-Fischer-Zentrum, Universität Erlangen-Nürnberg, Fahrstrasse 17, D-91054 Erlangen, Germany. E-mail: m.wegner@biochem.uni-erlangen.de.

DOI:10.1523/JNEUROSCI.5178-12.2013

Copyright $\odot 2013$ the authors $\quad 0270-6474 / 13 / 336679-12 \$ 15.00 / 0$
2012). To better understand how these transcription factors coordinate the myelination program, it is important to find out how they interact with and influence each other within their regulatory network and how they communicate with epigenetic factors and the basal transcription machinery.

Many cell-type-specific transcription factors communicate with the basal transcription machinery via the Mediator complex, which consists of $\sim 30$ subunits that are organized in three constitutive subcomplexes and a fourth optionally present, regulatory subcomplex that modulates the interaction between Mediator and RNA polymerase II (Borggrefe and Yue, 2011; Conaway and Conaway, 2011). The regulatory subcomplex is also referred to as the Srb8-11 or Cdk8 module and consists of Cdk8, cyclin C, Med12, and Med13.

Through gain-of-function and loss-of-function studies, the Mediator and its subunits have been implicated in the development of various cell types, tissues, and organs (Hentges, 2011). Intriguingly, some subunits are preferentially associated with specific developmental processes. For example, studies on Med12 revealed important contributions to the development of neural crest, nervous system, cartilage, kidney, and endodermal organs in vertebrate model organisms (Hong et al., 2005; Rau et al., 2006; Wang et al., 2006; Shin et al., 2008; Rocha et al., 2010; Zhou et al., 2012). Additional evidence for a role of Med12 in nervous system development came from human genetics: Med12 mutations have been identified as cause of intellectual disability syndromes, including Opitz-Kaveggia syndrome, and as risk factor for psychotic illnesses in Caucasians (Philibert, 2006; Risheg et al., 2007).

From phenotypic analyses of animal models and human patients, it is evident that Med12 is active in developing neurons. 
Here, we provide evidence that the role of Med12 in nervous system development is not restricted to neurons, but also extends to myelinating glia, where it appears to interact physically and functionally with the transcription factor Sox10 to drive the myelination process. Our study therefore provides important mechanistic insights into the pathway by which glial transcription factors interact with the general transcription machinery and instruct it to activate the myelination program.

\section{Materials and Methods}

Plasmids. Bacterial expression plasmids for fusion proteins between GST and Sox10 (Fig. 1A) have been described previously (Weider et al., 2012). For fusion proteins between GST and Med12-like (Med12l), sequences corresponding to the following regions of Med12l were amplified by PCR from mouse cDNA and inserted in-frame into the pGEX-KG vector by standard cloning procedures: amino acids 1753-1941, corresponding to the N-terminal half of the PQL domain (NPQL); amino acids 1840-2057, corresponding to the C-terminal half of the PQL domain (CPQL); and amino acids 2058-2157, corresponding to the OPA domain. In the context of pGEX-KG, several CPQL deletion mutants (CPQL del1-del6; Fig. $2 B$ ) were generated using the QuikChange XL Site-Directed Mutagenesis Kit (Stratagene), and CPQL was further subdivided into CPQL-1 (amino acids 1840-1913), CPQL-2 (amino acids 1911-1985), and CPQL-3 (amino acids 1983-2057).

Several Sox 10 and Med12l regions were also produced in bacteria as in-frame fusions to $\mathrm{N}$-terminal tandem $6 \mathrm{xHis}$ and $\mathrm{T} 7$ epitope tags using pET28-based vectors. This included dimerization and HMG domain (Dim/HMG), central conserved $\mathrm{K} 2$ domain, and C-terminal transactivation domain (TA) for Sox 10 (Weider et al., 2012), as well as the CPQL region and the complete C-terminal part (CT, corresponding to amino acids 1753-2157) for Med12l.

Eukaryotic expression vectors were based on the pCMV5 backbone and allowed expression of the following proteins or protein fragments: T7-tagged versions of full-length Med12, the Med12l CT and CPQL fragments, and untagged versions of Oct6 (Wegner et al., 1993), Sox10 (Kuhlbrodt et al., 1998), Sox10 $\Delta$ K2 (Schreiner et al., 2007), and Sox10VP16, in which the coding sequence of the VP16 transactivation domain was fused to amino acids 1-377 of rat Sox10. For gene-specific knock-down, shRNA coding sequences were inserted in wild-type or scrambled version into the pSuper vector according to the manufacturer's instructions (Oligoengine). Wild-type shRNA sequences included 5'-GCAGCAATGTCTGAGACTAAG-3' (shM1) and 5'-GCAGTATGC CACACACTTTCC-3' (shM2) for rodent Med12, 5' -GCATGCAGAGA GATAGCATTA-3' (sh8) for rodent Cdk8, 5'-GGAGGAAGGCTGA AACCATAC-3' (sh1) for rodent Med1, and 5'-GCTATCTCCTCTGAA GAAATC-3' (sh4) for rodent Med4.

The luciferase reporter plasmid carrying the Krox20 MSE was described previously (Reiprich et al., 2010). In case of the Oct6 Schwann cell enhancer (SCE), sequences corresponding to HR1 $a$ and $H R 2 b$ elements of the SCE (Jagalur et al., 2011) were amplified by PCR from mouse genomic DNA and inserted into a pGL3-based luciferase plasmid in front

C



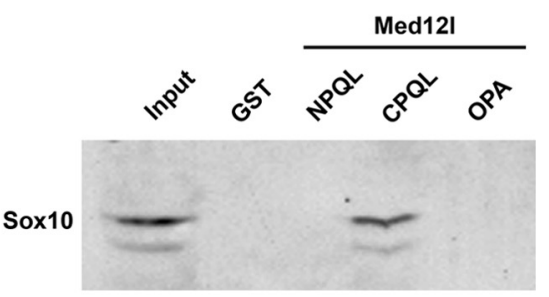

OPA

CPQL-3

1753 20572157 \begin{tabular}{l|l|} 
PQL & OPA \\
\hline
\end{tabular} CPQL

CPQL-1

CPQL-2

Med12I CT

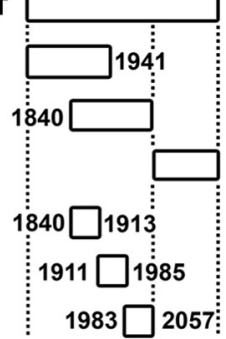

D

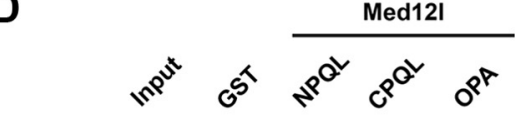



$\begin{array}{lllll}182 & 229 & 306 & 377 & 466\end{array}$



Figure 1. Sox10 and Med12l interact with each other. $\boldsymbol{A}$, In addition to full-length Med12, Med12I, and Sox10, fragments in interaction studies are schematically represented. Numbers represent amino acid positions. Conserved regions

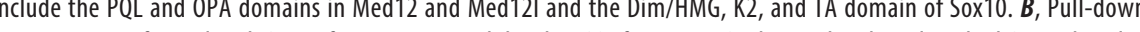
precipitated proteins by Western blot. Input corresponds to one-tenth of the amount of the protein used in the assay. Control pull-down experiments were performed with GST only.

of the $0.2 \mathrm{~kb}$ minimal promoter of the mouse Oct6 gene (Renner et al., 1996).

Generation of mice, tissue preparation, immunohistochemistry, and in situ hybridization. Med $12^{\Delta \mathrm{CNP1}}$ mutant embryos were generated by crossing Med $12^{\text {flox/flox }}$ females (Rocha et al., 2010) with males expressing Cre recombinase from the CNP1 locus (Lappe-Siefke et al., 2003). They were recovered by Cesarean section at $18.5 \mathrm{~d}$ post-coitum $(\mathrm{dpc})$ from staged pregnancies and genotyped as described previously (Lappe-Siefke et al., 2003; Rocha et al., 2010). Tissue underwent fixation with $4 \%$ paraformaldehyde before transfer to $30 \%$ sucrose and freezing in Tissue Freezing Medium (Leica). Next, $10 \mu \mathrm{m}$ cryotome sections at the forelimb level were used for immunohistochemical stainings (Stolt et al., 2003) with the following primary antibodies: guinea pig anti-Sox10 (1:1000 dilution; Maka et al., 2005), rabbit anti-Olig2 (1:500 dilution; Millipore), rabbit anti-Pdgfra (1:200 dilution; Santa Cruz Biotechnology), rabbit anti-Gpr17 (1:5000 dilution; Cayman Chemical), rabbit anti-Mrf (1:500 dilution; Julia Hornig and Michael Wegner, unpublished data), rabbit anti-Mbp (1:500 dilution; Neomarkers), rabbit anti-Sox2 (1:200 dilution; Thein et al., 2010), rabbit anti-Oct6 (1:2000 dilution; Renner et al., 1994), rabbit anti-Krox20 (1:200 dilution; Covance), and mouse antiNkx2.2 (1:5000 dilution; Hybridoma Bank). For antibodies directed against Nkx2.2 and Gpr17, signal intensity was enhanced by using the 




C

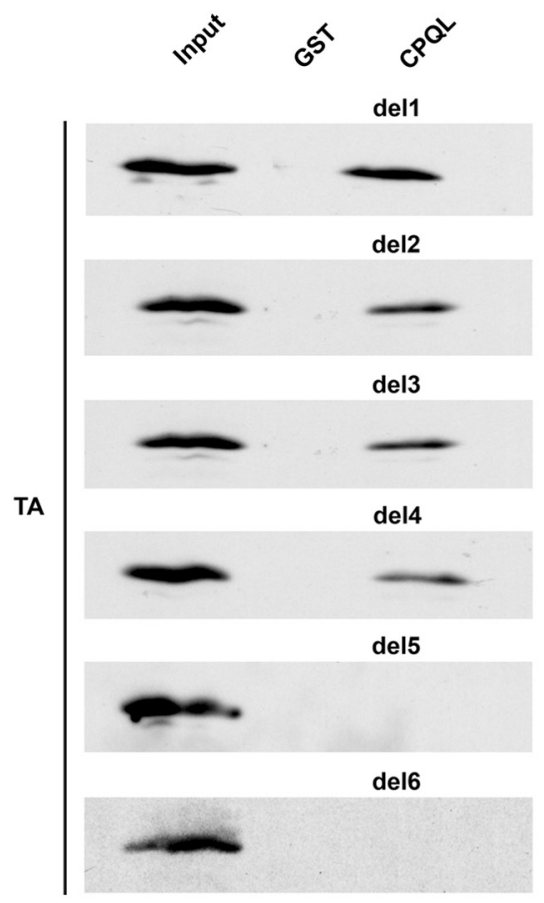

B



del1

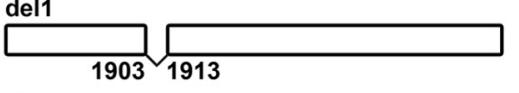

del2

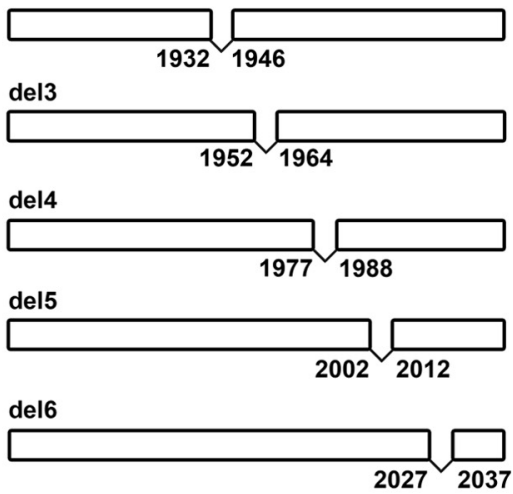

D

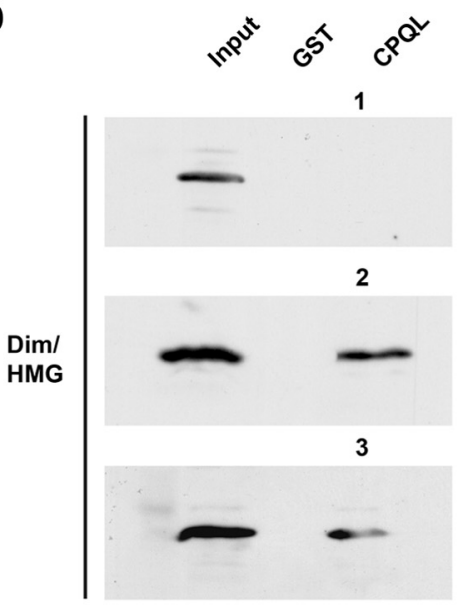

Figure 2. The interaction between Sox 10 and Med12l is mediated by multiple conserved regions in both proteins. A, Pull-down assays were performed with the Sox 10 transactivation domain immobilized as GST fusion on glutathione Sepharose beads and the T7-tagged Dim/HMG domain of Sox10 in the absence (top) or presence (bottom) of CPQL. B, Microdeletions del1- del6 were introduced into CPQL as outlined. Numbers define the deleted regions. C, Pull-down assays with GST fusions carrying CPQL and its deletion variants served to map the contact points for the Sox10 TA domain in Med12I. $\boldsymbol{D}$, The interaction interface between the Sox10 Dim/HMG domain and Med12I was investigated in pull-down assays with GST fusions carrying the CPQL subfragments 1-3 (Fig. 1A). The proteins to be pulled down are listed on the left of each panel and were all supplied as bacterially produced and purified versions. Detection was by Western blot using an antibody directed against the T7 epitope present in all proteins. Generally, input corresponds to one-tenth of the amount of the protein used in the assay. Control pull-down experiments were performed with GST only.

TSA-Plus Fluorescence system (PerkinElmer). Secondary antibodies were coupled to Cy3 or Alexa Fluor 488 fluorescent dyes (Dianova). Samples were documented with a Leica DMI 6000B inverted microscope equipped with a DFC 360FX camera (Leica).

For in situ hybridizations, $14 \mu \mathrm{m}$ cryotome sections from the forelimb level of mouse embryos were used with DIG-labeled antisense riboprobes specific for Mbp, Plp, and Mpz as described previously (Stolt et al., 2002). Samples were analyzed and documented with a Leica MZFLIII stereomicroscope equipped with an Axiocam (Zeiss).

Cell culture, transient transfection, extract preparation, and luciferase assays. Human 293 embryonic kidney cells, rat S16 Schwann cells (Toda et al., 1994), and rat OLN93 oligodendroglial cells (Richter-Landsberg and Heinrich, 1996) were maintained in DMEM containing 10\% fetal calf serum. Rat CG4 oligodendroglial cells and rat primary oligodendro- cytes were cultured in defined medium containing bFGF and PDGF and differentiated as described previously (Louis et al., 1992).

The 293 cells were transfected on $100 \mathrm{~mm}$ plates with $10 \mu \mathrm{g}$ of pCMV5-based expression plasmids using polyethylenimine and harvested $48 \mathrm{~h}$ after transfection for preparation of protein extracts (Wissmüller et al., 2006). OLN93 and S16 cells were also grown on 100 $\mathrm{mm}$ plates to obtain protein extracts.

Luciferase assays were performed in S16 cells grown on $35 \mathrm{~mm}$ plates and transfected in duplicates with Superfect reagent according to the manufacturer's protocol (Qiagen). Standard amounts of transfected plasmids per plate were $1 \mu \mathrm{g}$ for luciferase reporters, $0.8 \mu \mathrm{g}$ for pCMV5-based effector plasmid, and $0.2 \mu \mathrm{g}$ for pSuper plasmid. For synergistic activation, Sox10 and Oct6 expression plasmids were used in a 10:1 ratio. The total amount of expression plasmid was kept constant with empty pCMV5 plasmid, and luciferase activities were measured $48 \mathrm{~h}$ after transfection. In transfections with pSuper constructs, luciferase activities were normalized to luciferase activities observed with empty pCMV5 and the pSuper construct. Transfections were done at least three times. Analysis was performed with GraphPad Prism 5 software.

To achieve reproducibly high transfection efficiencies of $>50 \%$ for RNA studies in the S16 cell line, cells were transfected with $5 \mu \mathrm{g}$ of pSuper plasmids using the Xfect Transfection Reagent (Clontech) according to the manufacturer's protocol before RNA was prepared by the TRIzol method (Life Sciences Advanced Technologies).

Quantitative PCR analysis. RNA samples from mouse spinal cord, mouse sciatic nerve, untreated or transfected S16 cells, OLN93 cells, CG4 cells, primary Schwann cells, and oligodendrocytes were reverse transcribed and used to analyze expression levels by quantitative PCR (qPCR) on a Bio-Rad CFX96 Real Time PCR System. The following primer pairs were used: 5'-GGACGCTACTGAGTCACCTGG-3' and 5'-CCCAACAGTTCAATGTTTCAC-3' for mouse and rat Med12, 5'-ATTGCAGAG TTTGACTCATTC- $3^{\prime}$ and $5^{\prime}$-AAAGCGGAC ATATGGGACCAC-3' for mouse Med $12 l, 5^{\prime}$ AACCGGAGCGACTGTGTACAG- $3^{\prime}$ and $5^{\prime}$ GCTCAAGATTCTGAAGAATGC-3' for rat Med12l, 5'-AGGCCCCTTTGACCAGATGA-3' and 5'-AAGATGCCCGCACTCACAAT-3' for mouse Krox20, 5'-AGGGTTGCGACAGGA


for rat Krox20, 5'-GAAAACTGCAGTGGGAGGAAG-3' and 5'-GTA GGGGCTCCTCCTTGAAG-3' for mouse Nfatc4, $5^{\prime}$-GGTCACCATGTG GTCCTCGGATG-3' and 5' -AGGGTCTGAGAGGTCAATGCCAGG-3' for mouse $Y y 1$, and $5^{\prime}$-GAGAATGTTCAGAAACAGTGG-3' and 5'-GAA ATAGGTAGTGGAGCTGG-3' for mouse Gpr126. Transcript levels were normalized to $\beta$-actin. To be able to compare expression levels of Med 12 and Med12l directly in the same RNA sample, regions of similar size ( $\sim 200 \mathrm{bp}$ ) and with similar distance to the $3^{\prime}$ end $(\sim 2 \mathrm{kbp})$ were amplified from each transcript with primers of comparable efficiencies. Primer efficiencies were determined on cloned templates using the Bio-Rad CFX Manager software. They were all well over $90 \%$ and similar to each other.

GST pull-down assay, coimmunoprecipitation, and Western blotting. For GST pull-down assays, full-length proteins were produced in trans- 
fected 293 cells and used as whole-cell extracts. Sox10 and Med12l fragments were made in BL21 DE3 pLysS bacteria and further purified by affinity chromatography on glutathione-Sepharose 4B beads for GST fusion proteins or Ni-NTA beads for 6xHis-tagged proteins. The glutathione Sepharose $4 \mathrm{~B}$ bound GST or GST fusion proteins were incubated with cell extracts or 6xHis-tagged proteins for $2 \mathrm{~h}$ in buffer containing the following (in mM): $4.3 \mathrm{Na}_{2} \mathrm{HPO}_{4}, 1.47 \mathrm{KH}_{2} \mathrm{PO}_{4}, 100 \mathrm{NaCl}$, and $2.7 \mathrm{KCl}$, followed by repeated cycles of centrifugation and washing.

For coimmunoprecipitation, S16 and OLN93 cell extracts were diluted 1:5 in $10 \mathrm{~mm}$ HEPES, pH 7.9, $0.1 \mathrm{~mm}$ EDTA, 0.1 mм EGTA, $100 \mathrm{~mm}$ $\mathrm{NaCl}, 10 \%$ glycerol, $10 \mu \mathrm{g} / \mathrm{ml}$ aprotinin, $10 \mu \mathrm{g} / \mathrm{ml}$ leupeptin, and $2 \mathrm{~mm}$ DTT before the addition of rabbit antiserum against Sox10 (1:3000 dilution; Stolt et al., 2003) or control preimmune serum and protein A Sepharose CL-4B beads (GE Healthcare). After overnight incubation at $4^{\circ} \mathrm{C}$ samples underwent repeated cycles of centrifugation and washing.

Bead-bound proteins in GST-pull-down assays and coimmunoprecipitations were eluted and size fractionated on polyacrylamide-SDS gels. Detection was by Western blot using mouse antibodies directed against the T7 epitope tag (1:10,000 dilution; Novagen), rabbit antisera against Sox10 (1:3000 dilution), Med12 (1:5000 dilution; Novus Biologicals), Med1 (1:200 dilution; Santa Cruz Biotechnology sc-8998), and Med15 (1:200 dilution; Santa Cruz Biotechnology sc-86730), as well as goat antisera against Med13 (1:200 dilution; Santa Cruz Biotechnology sc12013) and Cdk8 (1:200 dilution; Santa Cruz Biotechnology sc-1521).

Chromatin immunoprecipitation. Chromatin was prepared from S16 cells after cross-linking of endogenous proteins to DNA and shearing as described previously (Weider et al., 2012). Immunoprecipitation was overnight at $4^{\circ} \mathrm{C}$ using Med 12 antibodies or control immunoglobulins in the presence of protein A Sepharose CL-4B beads pretreated with BSA and salmon sperm DNA. After washing, cross-link reversal, proteinase K treatment, phenol/chloroform extraction, and ethanol precipitation, the amount of DNA from input and precipitated chromatin was quantified by qPCR using the Bio-Rad CFX96 Real Time PCR system (Weider et al., 2012). To detect various regions around the Krox20 gene the following primer pairs were used: 5' -CCAGGCTGGAGATGAGAGTC-3' and 5' GTGTCCCACCCTCTGAAAAA-3' to amplify positions -2262 to -2069 (-2 region), 5' -ACAAACAAACAGCCCAGACC-3' and 5' -AAA AATTACCCGCACTCACG-3' to amplify positions -742 to -585 (-0.6region), $5^{\prime}$-CCAAGCCCGTATGCAAAT- $3^{\prime}$ and $5^{\prime}$-CTCGCCCAG CAATTAATGA- $3^{\prime}$ to amplify positions -149 to +24 around the transcriptional start (TS region), 5' -AATCCACGAATGAGGAGGTG-3' and 5'-GATCTGGAACCTAGCGATGC-3' to amplify positions +36184 to +36352 (+36 region) and 5'-AGCCCTTCACAAAGCTGAAA- $3^{\prime}$ and $5^{\prime}$-GGATTTCATCCTTGGCTTCA-3' to amplify positions +39984 to +40234 within the MSE.

\section{Results}

Sox10 interacts with Med12-like and its close relative Med12

A yeast-two-hybrid screen for interactors of dimerization and HMG domains of Sox10 led to the identification of the C-terminal part of Med12-like (Med12l). This region consists of the proline-, glutamine-, and leucine-rich PQL and the adjacent glutamine-rich OPA domain, and exhibits $67 \%$ amino acid similarity to the corresponding region of Med12 (Fig. 1A). Although little is known about Med12l, it may function similarly to Med12.

To confirm the yeast-two-hybrid result, we first performed GST pull-down experiments. In these experiments, we tried to precipitate the C-terminal region of Med12l (Med12l CT, corresponding to amino acids 1753-2157; Fig. 1A) from extracts of transiently transfected 293 cells by GST fusion proteins that carried various domains of Sox10 and were immobilized on glutathione-Sepharose beads. As expected from the yeast-twohybrid study, Med12l CT bound to a GST fusion protein containing dimerization and HMG domains (Dim/HMG) of Sox10 (Fig. $1 B$ ). Interestingly, Med12l CT also interacted with the C-terminal transactivation domain (TA) of Sox10, but not with its central conserved region $(\mathrm{K} 2)$.
Interaction between the two proteins was also observed when GST-Med12 fusion proteins were used (Fig. 1C). Sox10 was pulled down from extracts of transfected 293 cells by a bacterially produced GST fusion protein carrying the C-terminal half of the PQL domain of Med12l (CPQL, corresponding to amino acids 1840-2057; Fig. $1 C)$. In contrast, the $\mathrm{N}$-terminal part of the PQL domain (NPQL, corresponding to amino acids 1753-1941), and the OPA domain (corresponding to amino acids 2058-2157) failed to pull down Sox10 (Fig. 1C). These experiments map the interaction site within Med12l between amino acids 1840 and 2057.

Interaction was also observed when Sox10 and Med12l domains were both produced in bacteria and purified before the GST pull-down experiment (Fig. 1D). The Dim/HMG and TA domains of Sox 10 both interacted with the CPQL region, but not with the NPQL or OPA region, whereas the K2 domain of Sox10 failed to interact with any of these regions. From these results, we conclude that Sox10 and Med12l can interact with each other without eukaryote-specific posttranslational modifications, because these were absent in the bacterially expressed proteins.

Considering that the Dim/HMG and TA regions interacted with the CPQL region of Med12l, we investigated whether binding of both Sox 10 regions was mutually exclusive or if it could occur simultaneously. We first verified by GST pull-down that the two Sox10 regions did not already interact with each other in the absence of Med12l. The Sox10 TA domain was fused to GST and the Dim/HMG domain was produced in bacteria with tandem $6 \times \mathrm{xHis}$ and $\mathrm{T} 7 \mathrm{tags}$ for purification and detection. When these two bacterially expressed purified proteins were used in a GST pull-down experiment, no interaction was detected (Fig. 2A, top). However, when a bacterially produced, $\mathrm{T} 7$-tagged protein corresponding to CPQL was added, Dim/HMG was specifically precipitated (Fig. $2 A$, bottom). This strongly suggests that both Sox10 domains are able to simultaneously bind to the CPQL region of Med12l.

To further delineate the interacting region in CPQL, we introduced several microdeletions (Fig. 2B). These deletions were chosen such that $\sim 10$ consecutive amino acids with a high degree of conservation between Med12l and Med12 were removed. When the resulting GST-CPQL fusions were incubated with the TA domain of Sox 10, interactions remained unaffected by deletions del1-del4 (Fig. 2C). In contrast, CPQL del5 and del6 had lost their ability to bind the TA domain of Sox10. This maps the interface for TA domain recognition between amino acids 2002 and 2037 of Med12l.

We also performed analogous experiments with the Dim/ HMG domain of Sox10; however, none of the deletions abolished the interaction of the Dim/HMG domain with CPQL (data not shown). This suggests that either none of the deleted regions is involved in the interaction or that there are multiple contacts for Dim/HMG within CPQL, each sufficient to mediate interaction in GST pull-down assays. To differentiate between these possibilities we divided CPQL into CPQL-1 (corresponding to amino acids 1840-1913), CPQL-2 (corresponding to amino acids 19111985), and CPQL-3 (corresponding to amino acids 1983-2057) (Fig. 1A). When these CPQL subfragments were produced as GST fusions and tested for their ability to pull-down the Dim/ HMG domain, both CPQL-2 and CPQL-3, but not CPQL-1, were able to interact (Fig. 2D). This indicates that there are at least two separate contact regions for Dim/HMG between amino acids 1911 and 2057 of Med12l.

Considering the high degree of conservation between Med12l and Med12 in the interacting region, it seemed likely that Sox10 
A
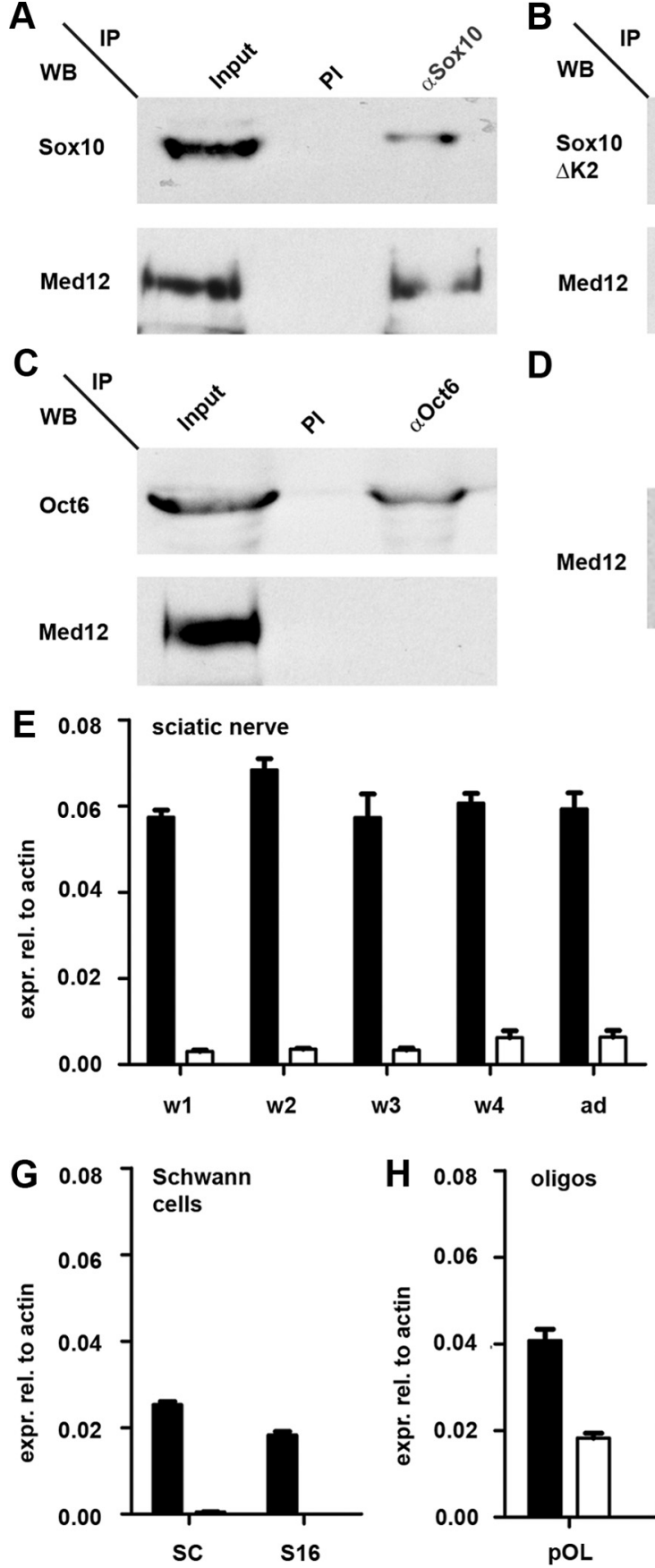

B



Med12

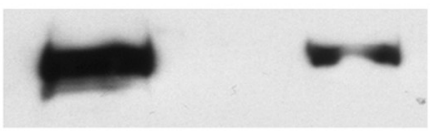

D

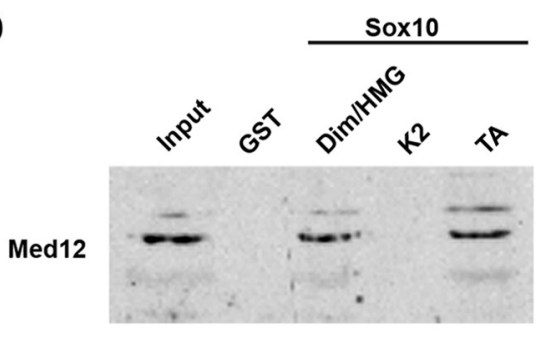

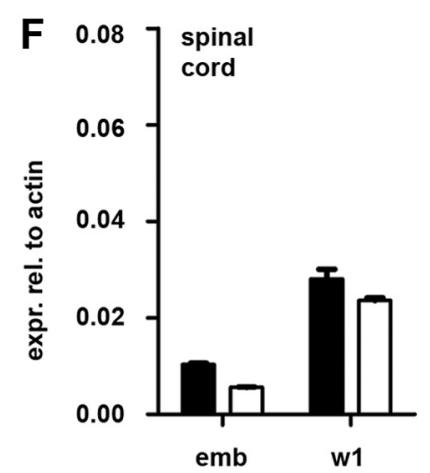

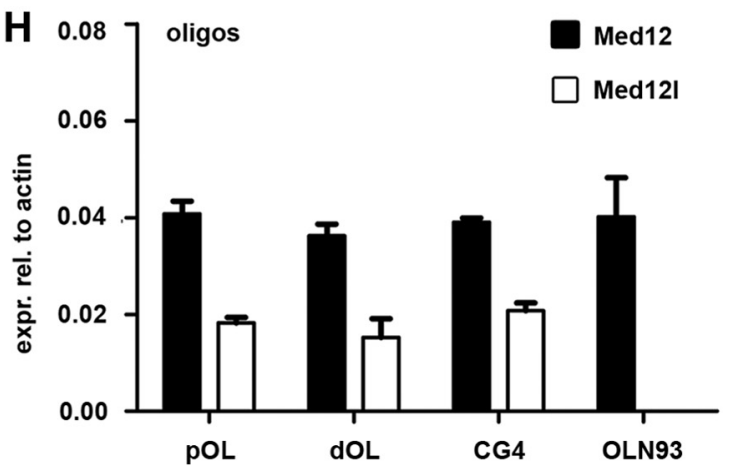

Figure 3. Sox 10 and Med12 interact and are coexpressed in glia. $\boldsymbol{A}$-C, Full-length, T7-tagged Med 12 was coexpressed with Sox10 (A), Sox10 $\Delta$ K2 $(\boldsymbol{B})$, or 0ct6 $(\boldsymbol{C})$ in 293 cells and analyzed for its ability to interact with these proteins in coimmunoprecipitation (IP) assays. Antisera directed against Sox10 $(\alpha$ Sox 10$)$ or $0 \mathrm{ct} 6(\alpha 0 \mathrm{ct} 6)$ and preimmune serum (PI) were used. Top, Western blot (WB) detection of Sox10 (A, B) or 0ct6 (C). Bottom, Western blot detection of Med12 using specific antibodies. Input corresponds to one-tenth of the amount of the protein used in the assay. D, Conserved Sox 10 regions Dim/HMG, K2, and TA were fused to GST and used in pull-down assays to precipitate T7-tagged Med12. Med12 in the precipitate was detected by Western blot using an antibody directed against the T7 epitope. $\boldsymbol{E}-\boldsymbol{H}$, Expression levels of Med12 (black bars) and Med12l (white bars) were determined by qRT-PCR in RNA prepared from sciatic nerve $(\boldsymbol{E})$ during postnatal weeks $1,2,3$, and 4 (w1, w2, w3, w4) and in the adult (ad), from embryonic (emb) and postnatal (w1) spinal cord (F), from primary Schwann cells (SC) and the S16Schwann cell line (G), and from primary oligodendrocytes kept under proliferating (pOL) or differentiating (dOL) conditions, as well as $\mathrm{CG} 4$ and $0 \mathrm{LN} 93$ cell lines $(\boldsymbol{H})$. Transcript levels were normalized to $\beta$-actin levels in the respective samples. For each RNA source, RT-PCRs were performed on at least three independent samples.

also interacted with Med12. To confirm this assumption, we overexpressed T7-tagged full-length Med12 and full-length Sox10 in 293 cells and performed coimmunoprecipitation experiments. Med12 was specifically detected in the precipitate ob-

tained with an anti-Sox10 antiserum, but not with preimmune serum (Fig. $3 A$ ). Med12 was also coprecipitated when Sox10 was replaced by a version that lacked the K2 domain (Sox10 $\Delta$ K2; Fig. $3 B)$. In contrast, no interaction was evident between Med12 and the Oct6 transcription factor after ectopic expression of both proteins in 293 cells and precipitation with an anti-Oct6 antiserum (Fig. 3C). Extracts from Med12transfected 293 cells were also used in pull-down studies with fusions between the GST and Sox10 regions (Fig. 3D). As was observed previously for the C-terminal part of Med12l, full-length Med12 also interacted with the Dim/ HMG region and the TA domain of Sox10, but not with the K2 domain. We therefore conclude that Med12 and Med12l interact similarly with Sox10.

\section{Interaction between Sox 10 and Med12 occurs in glial cells under physiological conditions}

For a protein-protein interaction to be physiologically relevant, both proteins have to occur in the same cells. Because Sox10 is prominently expressed in glial cells of the nervous system (Kuhlbrodt et al., 1998), we analyzed by qRT-PCR whether these cells also express Med12l and Med12. By choosing primer pairs of comparable location, properties, and efficiencies, and by normalizing to $\beta$-actin, transcript levels could be compared for each gene between samples and between Med12l and Med12. The sciatic nerve as a Schwann-cell-enriched PNS region exhibited a robust Med12 expression at all analyzed time points with only little fluctuation (Fig. 3E). Med12l was also detected in the sciatic nerve, but at significantly lower levels. Compared with the sciatic nerve, the amount of Med12 transcripts was lower in the spinal cord as an oligodendrocyte-rich region of the CNS (Fig. $3 F$ ). Med12 transcripts were found both in late embryonic and in early postnatal spinal cord. Amounts of Med12l transcripts were again lower than those for Med12; however, the difference was less pronounced than in the sciatic nerve.

Both sciatic nerve and spinal cord contain cell types other than Sox10expressing glia. To confirm colocalization with Sox10 at the cellular level, we performed additional RT-PCR analyses on RNA from Schwann cell and oligodendrocyte cultures. In RNA from cultured primary Schwann cells and the S16 Schwann cell line, Med12 was present in substantial amounts (Fig. 3G). In contrast, amounts of Med12l transcripts were at the detection 
limit. This difference in expression level is compatible with previous findings from microarray studies (Buchstaller et al., 2004). Cultured primary oligodendrocytes also expressed Med12 at robust levels independently of whether they were kept under proliferating or differentiating conditions (Fig. 3H). Again, this supports previous data from expression profiling studies that failed to detect substantial changes in Med12 transcript levels during oligodendroglial development (Dugas et al., 2006; Nielsen et al., 2006). Comparably strong Med 12 expression was observed in CG4 and OLN93 as two oligodendroglial cell lines (Fig. 3H). For Med12l, transcripts were detected in RNA from primary oligodendrocytes and CG4 cells, but not in RNA from OLN93 cells. When present, transcript levels were again lower for Med12l than for Med12. From these results, we conclude that Med12 is coexpressed with Sox10 in Schwann cells and oligodendrocytes. In contrast, Med12l occurs at lower levels in oligodendrocytes and may even be absent from Schwann cells. Considering the expression profiles and the lack of antibodies and mouse mutants for Med121, we chose to focus all further studies on Med12.

The presence of Sox10 and Med12 in Schwann cells and oligodendrocytes prompted us to perform coimmunoprecipitation on extracts from S16 and OLN93 cells (Fig. $4 A, B)$. After precipitation of endogenous Sox 10 from these extracts with specific antibodies, we detected not only Sox 10 in the precipitate (Fig. $4 A, B$, top), but also endogenous Med12 (Fig. $4 A, B)$. Neither protein was detected when preimmune antiserum was used instead of the Sox 10 antiserum. These results suggest that the interaction between Sox 10 and Med12 occurs under physiological conditions and at physiological concentrations in Schwann cells and oligodendrocytes.

Considering that Med12 has unique functions not attributed to other subunits of the Mediator complex and usually occurs as part of the CDK8 module (Borggrefe et al., 2002), we also analyzed whether other subunits of the CDK8 module were coimmunoprecipitated with Sox10. Indeed, Med13 and Cdk8 were also found in the precipitate (Fig. $4 A, B$ ), indicating that Sox 10 can interact with the complete CDK8 module in Schwann cells and oligodendrocytes.

The CDK8 module can reversibly associate with the other three constitutive modules of the Mediator complex to modulate its coactivator function in a repressive or stimulatory manner (Donner et al., 2007; Knuesel et al., 2009a; Belakavadi and Fondell, 2010). In addition, the CDK8 module has functions apart from the rest of the Mediator complex (Ding et al., 2008; Knuesel et al., 2009b). Precipitates obtained from Schwann cells or oligodendrocytes with an anti-Sox10 antiserum also contained Med 1 from the middle module and Med15 from the tail module of the Mediator complex (Fig. 4A,B). This suggests an ability of Sox10 to interact with the complete Mediator complex in both glial cell types; at the same time, it does not exclude that Sox10 may also interact with the isolated CDK8 module or Med12 protein.
B

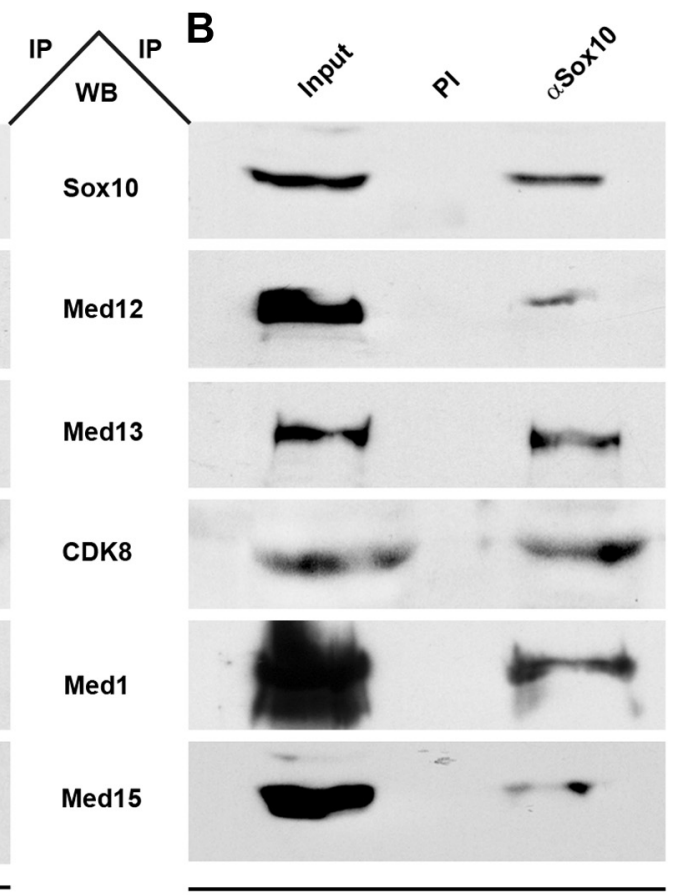

16
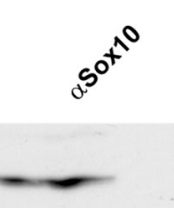

sam:
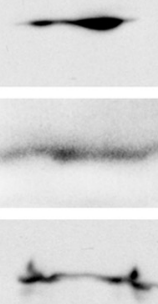

$n+4$
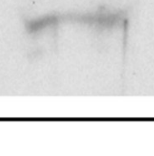

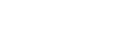

\section{OLN93}

Figure 4. Sox10 interacts with Med12 and the Mediator complex under physiological conditions. $A, B$, Coimmunoprecipitation (IP) of endogenous Med12 and other mediator subunits with anti-Sox10 antiserum ( $\alpha$ Sox 10 ) or preimmune serum (PI) from S16 $(\boldsymbol{A})$ and OLN93 $(\boldsymbol{B})$ cell extracts. Top, Western blot (WB) detection of Sox10. Bottom panels probe the presence of Med12, Med13, Cdk8, Med1, and Med15 in the precipitate using antibodies specifically directed against the respective protein. Input corresponds to one-tenth of the amount of the protein used in the assay.

\section{Mice with glia-specific Med12 deletion exhibit defects in glial} differentiation and myelin gene expression

If the physical interaction is functionally relevant, Med12 should have a role in the development of Schwann cells and oligodendrocytes. To test this hypothesis in vivo, we deleted Med12 in the mouse. Considering that Med12-deficient mice already die before the end of gastrulation and that hypomorphic mutants already exhibit severe and early defects in the developing nervous system that may impede the analysis of glial development at later time points, we chose to delete the X-chromosome-linked Med12 gene specifically in the already specified glial lineages using the recently described floxed Med12 allele (Rocha et al., 2010) and a CNP1-Cre knock-in allele (Lappe-Siefke et al., 2003). These were combined in a Med12 $2^{\mathrm{fl} / \mathrm{y}} \mathrm{CNP} 1^{+/ \mathrm{cre}}$ genotype, hereafter referred to as Med12 ${ }^{\Delta \mathrm{CNP} 1}$. Similar to CNP1 itself, Cre recombinase is already expressed very early during Schwann cell development, whereas its expression in developing oligodendrocytes is delayed and only sets in at the promyelinating stage shortly before the cells start to undergo terminal differentiation.

Med $12^{\Delta \mathrm{CNP} 1}$ mice died shortly after birth, so analysis was confined to the embryonic and perinatal stages. The cause of death is unknown, but is unlikely to result from the phenotype observed in glial lineages. At embryonic day $15.5, \mathrm{Med} 12^{\Delta \mathrm{CNP} 1}$ embryos did not exhibit any obvious alterations of glial cell development in the PNS or CNS (data not shown). At this time, Med12 was already deleted from most Schwann cells, whereas it was still expressed in the vast majority of oligodendroglial cells. In the latter, Med12 deletion became detectable only at embryonic day 18.5 and was restricted at this stage to a fraction of oligodendroglial cells found in the marginal zone, which is consistent with the onset of Cre expression in promyelinating oligodendrocytes. 


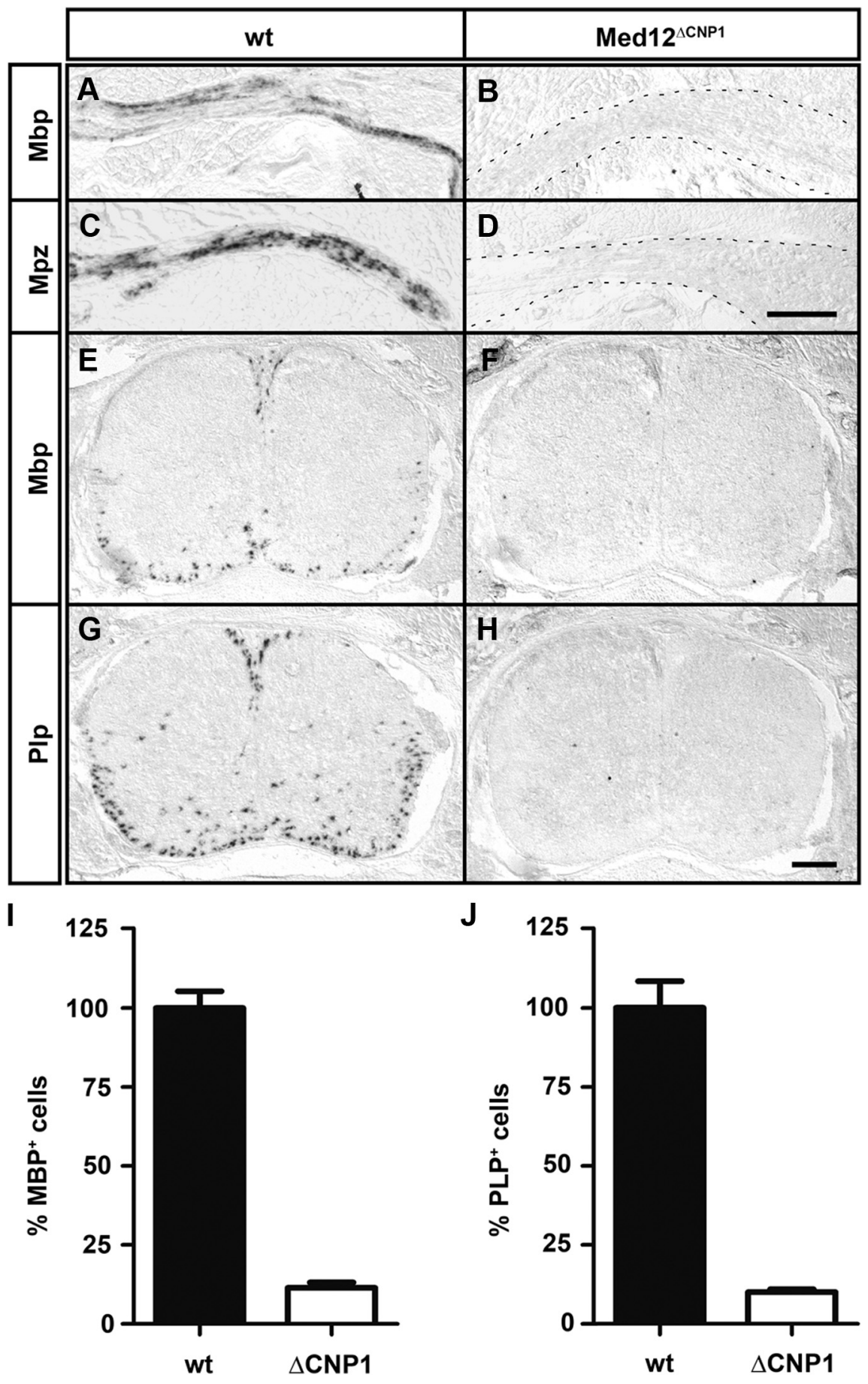

Figure 5. Myelin expression is absent from mouse PNS and CNS in the absence of Med12. $\boldsymbol{A}-\boldsymbol{H}$, In situ hybridizations were performed on wild-type embryos $(\boldsymbol{A}, \boldsymbol{C}, \boldsymbol{E}, \boldsymbol{G})$ and $\operatorname{Med} 12^{\Delta \mathrm{CNP} 1}$ littermates $(\boldsymbol{B}, \boldsymbol{D}, \boldsymbol{F}, \boldsymbol{H})$ at embryonic day 18.5 with probes directed against $\operatorname{Mbp}(\boldsymbol{A}, \boldsymbol{B}, \boldsymbol{E}, \boldsymbol{F}), \operatorname{Mpz}(\boldsymbol{C}, \boldsymbol{D})$, and $P l p(\boldsymbol{G}, \boldsymbol{H})$. Shown are spinal nerve $(\boldsymbol{A}-\boldsymbol{D})$ and spinal cord $(\boldsymbol{E}-\boldsymbol{H})$ in transverse section. Size bars correspond to $200 \mu \mathrm{m}$ with the bar in $\boldsymbol{D}$ being valid for $\boldsymbol{A}-\boldsymbol{D}$ and the one in $\boldsymbol{H}$ for $\boldsymbol{E}-\boldsymbol{H}$. $\boldsymbol{I}, \boldsymbol{J}$, Quantification of $M b p$ - and PIp-positive cells in the wild-type and mutant spinal cord at embryonic day 18.5. Numbers in the wild-type spinal cord were set to $100 \%$. At least five separate $14 \mu \mathrm{m}$ sections from the forelimb region of two independent embryos were counted for each genotype. Data are presented as mean \pm SEM. Differences from the wild-type were statistically significant as determined by the Student's t test $(p \leq 0.001)$.

A common denominator of Schwann cell and oligodendrocyte development is that both cell types start to induce the expression of several major myelin genes, including $M b p, M p z$, and $P l p$ around the time of birth as part of the terminal differentiation program. To assess whether there is an effect on glial develop- ment in $\operatorname{Med} 12^{\Delta \mathrm{CNP1}}$ mice until their time of death, we performed in situ hybridizations with probes directed against several myelin-gene-specific transcripts on embryos at $18.5 \mathrm{dpc}$. Although $\mathrm{Mbp}$ and $M p z$ transcripts were readily detected in spinal nerves of wild-type embryos, $\operatorname{Med} 12^{\Delta \mathrm{CNP} 1}$ littermates exhibited almost no expression of either myelin gene (compare Fig. $5 A, C$ and Fig. $5 B, D$ ). Similarly, $M b p$ and $P l p$ transcripts were present in the marginal zone of the thoracic spinal cord at this age in the wild-type, but largely absent from the spinal cord of Med $12^{\Delta \mathrm{CNP} 1}$ embryos (compare Fig. $5 E, G$ with Fig. $5 F, H)$. We detected only rarely a few $M b p$-positive or $P l p$-positive cells in the Med12 ${ }^{\Delta \mathrm{CNP} 1}$ spinal cord. Quantification confirmed the dramatic difference between these genotypes (Fig. $5 I, J)$. These findings allow us to conclude that terminal differentiation and myelin gene expression is disturbed in both Schwann cells and oligodendrocytes of Med $12^{\Delta \mathrm{CNP} 1}$ mice.

To further characterize the defects, we performed additional immunohistochemical stainings on embryos at 18.5 dpc. We used antibodies directed against Sox10 on peripheral nerves (Fig. $6 A, B$ ). These stainings indicated that the number of Sox10-positive cells in the nerve is unaltered in $\mathrm{Med} 12^{\Delta \mathrm{CNP1}}$ embryos. Antibodies directed against the Sox 2 and Oct6 transcription factors similarly failed to detect any differences between wild-type and Med $12^{\Delta \mathrm{CNP} 1}$ embryos with Sox2 already downregulated and Oct6 being widely upregulated in Schwann cells along the nerve (Fig. $6 C-F$ ). This indicates that Schwann cells had reached the promyelinating stage of their development. In contrast, Krox20 expression was strongly reduced in nerves of $\mathrm{Med} 12^{\Delta \mathrm{CNP} 1} \mathrm{em}$ bryos compared with their wild-type littermates (Fig. 6G,H). Quantifications confirmed the findings in all cases (Fig. $6 I, J$ and data not shown).

The dramatic reduction of Krox20 was also confirmed on the transcript level in quantitative RT-PCR studies on sciatic nerves from $18.5 \mathrm{dpc}$ wild-type and Med $12^{\Delta \mathrm{CNP} 1}$ embryos (Fig. $6 \mathrm{~K}$ ). In contrast, levels of $Y y 1$ and $N$ fatc 4 as two other regulators of Schwann cell development remained unaltered, whereas amounts of Gpr126 transcripts were increased (Fig. $6 K)$. Considering that Krox20 is the main Schwann cell regulator with decreased expression in Med $12^{\Delta \mathrm{CNP} 1}$ mice and that it is normally upregulated early during differentiation and required for the execution of the myelination program, it is concluded that Schwann cell development is specifically arrested at the onset of myelination. 
Immunohistochemical analyses were also performed on oligodendroglial cells in the embryonic spinal cord at embryonic day 18.5. Olig2, as a marker of cells belonging to the oligodendroglial lineage, was indistinguishably present in the mantle zone and marginal zone of agematched wild-type and $\mathrm{Med} 12^{\Delta \mathrm{CNP} 1}$ embryos (Fig. 7A-D; for location of depicted areas, Fig. $7 U$ ). The number and distribution of Pdgfra-positive oligodendrocyte precursor cells was also very similar in wild-type and age-matched Med $12^{\Delta \mathrm{CNP} 1}$ embryos (Fig. $7 E-H$ ); if anything, there was a slight increase in the number of Pdgfra-positive cells in the marginal zone of Med12 ${ }^{\Delta \mathrm{CNP} 1}$ embryos. This suggests that oligodendroglial cells in general, as well as the fraction of oligodendrocyte precursors, are not strongly affected in number or distribution by the Med12 deletion.

This was also confirmed by immunohistochemical stainings for Sox10 as an alternative marker for the oligodendroglial lineage (Fig. 7I-L). The only conspicuous difference between wild-type and agematched $\operatorname{Med} 12^{\Delta \mathrm{CNP1}}$ embryos was in staining intensities. Those oligodendrocytes that started terminal differentiation in the marginal zone of wild-type embryos at $18.5 \mathrm{dpc}$ were recognizable by higher Sox10 amounts compared with oligodendrocyte precursors of the mantle or marginal zone (compare Fig. $7 I$ and Fig. $7 \mathrm{~K}$ ). In $\mathrm{Med} 12^{\Delta \mathrm{CNP1}}$ embryos, however, all Sox10-positive cells exhibited comparable staining intensities that further resembled those of oligodendrocyte precursors in the wild-type (Fig. $7 I, J, L)$. The missing upregulation of Sox10 in the marginal zone of the Med $12^{\Delta \mathrm{CNP} 1}$ spinal cord may be indicative of a failure to initiate terminal oligodendrocyte differentiation. This assumption was confirmed by strong alterations in the expression of terminal oligodendrocyte markers in Med12 ${ }^{\Delta \mathrm{CNP} 1}$ embryos. Both Nkx2.2 and Gpr17 are induced at the very onset of the differentiation process, immediately followed by Mrf (Qi et al., 2001; Chen et al., 2009; Emery et al., 2009). Accordingly, all three proteins were detected at $18.5 \mathrm{dpc}$ in the marginal zone of the wild-type spinal cord (Fig. $7 M, O, Q)$, but Gpr17 and Mrf were mostly absent from spinal cords of Med12 ${ }^{\Delta \mathrm{CNP} 1}$ littermates (Fig. $7 N, P, R$ ). In the absence of these transcriptional regulators of the myelination program, $\mathrm{Mbp}$ was also missing in the marginal zone of the Med12 $2^{\triangle \mathrm{CNP} 1}$ spinal cord (Fig. 7S, T). Similar to the situation in Schwann cells, oligodendrocyte development thus appears to be stalled at the very onset of terminal differentiation and myelination.

Med12 interacts functionally with Sox10 during terminal glial differentiation and myelination

Considering that Med12 is similarly involved in terminal differentiation of myelinating glia as Sox10 and that both proteins interact physically, it seems reasonable to assume that these proteins cooperate functionally during these processes. It has been shown previously that Sox10 binds to the MSE enhancer of the
Krox20 gene in Schwann cells (Ghislain and Charnay, 2006; Reiprich et al., 2010). If Sox10 and Med12 cooperate, we would predict that Med12 is also located at the MSE enhancer. To test this hypothesis, we performed chromatin immunoprecipitation on S16 Schwann cells that actively transcribe Krox20 (Fig. 8A). These experiments showed that the Krox20 MSE was significantly enriched in chromatin precipitated with anti-Med12 antibody relative to chromatin precipitated with control immunoglobulins (Fig. $8 B-D$ ). A similar enrichment was also found for the transcription start site of the Krox20 gene, but not for several control fragments in the upstream or downstream regions of the gene (Fig. $8 B, D$ ). Therefore, like Sox10, Med12 is bound to the MSE in S16 Schwann cells.

To further exploit S16 cells as a system with which to study Med12 interaction with Sox10, we generated two shRNAs directed against rodent Med12. After validation of these shRNAs in Med12-transfected 293 cells (Fig. 8E) and in S16 cells (Fig. 8F), we first studied their impact on endogenous Krox20 expression. In agreement with all other data, both Med12-specific shRNAs substantially reduced Krox20 levels in S16 cells, whereas a scrambled version failed to do so (Fig. 8G). We further performed reporter gene assays in S16 cells by transient transfection of a luciferase gene under control of the Krox20 MSE (Fig. 8H-K). As described previously (Reiprich et al., 2010), this luciferase reporter is activated by cotransfected Sox10 (Fig. $8 H$ ). Activation was substantially reduced in the presence of either shRNA di- 


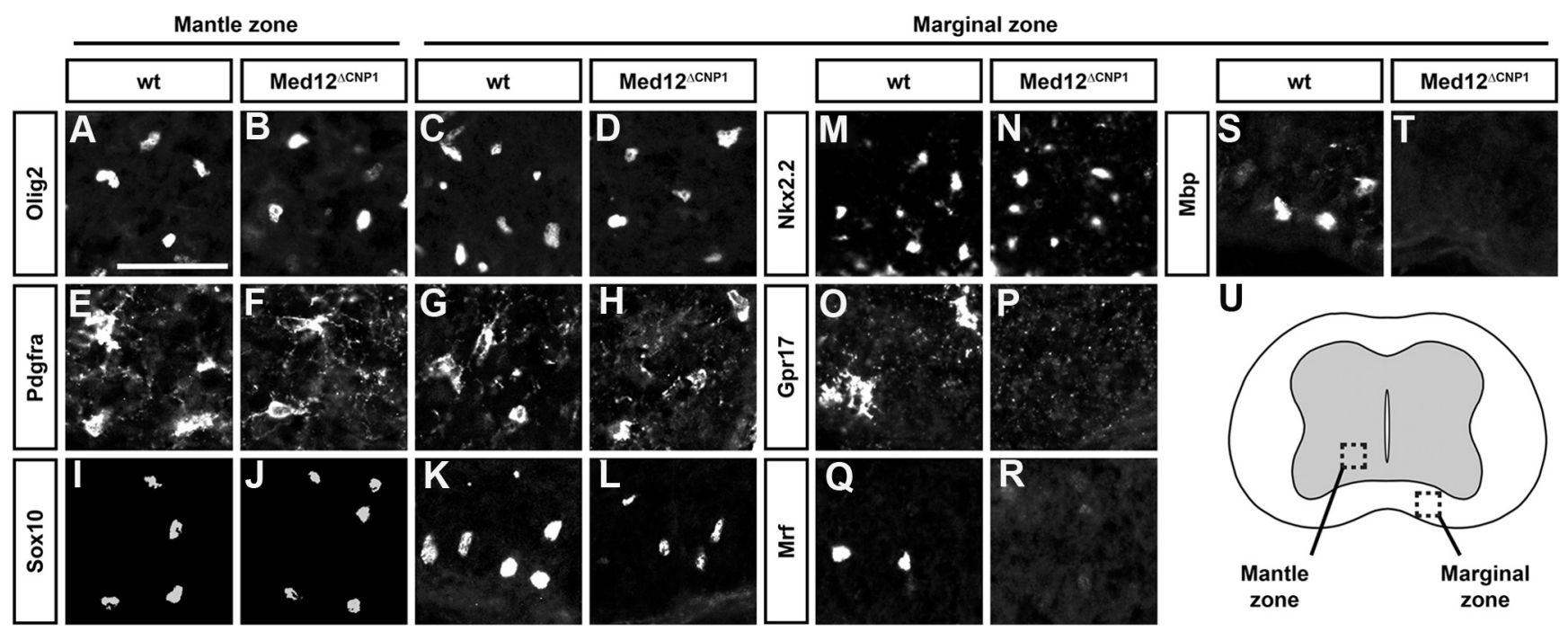

Figure 7. In the absence of Med12 oligodendrocytes fail to induce the myelination program. Immunohistochemistry was performed on transverse spinal cord sections of wild-type embryos $(\boldsymbol{A}, \boldsymbol{C}, \boldsymbol{E}, \boldsymbol{G}, \mathbf{I}, \boldsymbol{K}, \boldsymbol{M}, \mathbf{O}, \mathbf{Q}, \boldsymbol{S})$ and $M e d 12^{\Delta \mathrm{CNP} 1}$ littermates $(\boldsymbol{B}, \boldsymbol{D}, \boldsymbol{F}, \boldsymbol{H}, \boldsymbol{J}, \boldsymbol{L}, \boldsymbol{N}, \boldsymbol{P}, \boldsymbol{R}, \boldsymbol{I})$ at embryonic day $18.5(\boldsymbol{A}-\boldsymbol{R})$ or immediately after birth $(\boldsymbol{S}, \boldsymbol{T})$ with antibodies directed against 0 lig2 $(\boldsymbol{A}-\boldsymbol{D}), \mathbf{P d g f r a}(\boldsymbol{E}-\boldsymbol{H})$, Sox10 (I-L), Nkx2.2 (M,N), Gpr17 (O, P), Mrf $(\boldsymbol{Q}, \boldsymbol{R})$, and $\operatorname{Mbp}(\boldsymbol{S}, \boldsymbol{T})$. Photographs were taken both from the mantle zone $(\boldsymbol{A}, \boldsymbol{B}, \boldsymbol{E}, \boldsymbol{F}, \boldsymbol{I}, \boldsymbol{J})$ and the marginal zone $(\boldsymbol{C}, \boldsymbol{D}, \mathbf{G}, \boldsymbol{H}, \boldsymbol{K}-\boldsymbol{T})$ of the ventral spinal cord as schematically indicated in $\boldsymbol{U}$. Scale bar, $50 \mu \mathrm{m}$.

rected against $\mathrm{Med} 12$, whereas a shRNA with scrambled sequence had no effect (Fig. $8 H$ ). This suggests that Sox10 depends, at least in part, on Med12 for Krox20 induction.

The MSE-containing luciferase reporter was also activated when wild-type Sox10 was replaced by a chimeric version in which its C-terminal TA domain was replaced by the transactivation domain of VP16 (Fig. 8I). Intriguingly, activation by the Sox10-VP16 fusion was refractory to the presence of Med12specific shRNA. VP16 predominantly interacts with the Mediator complex via the Med25 subunit (Mittler et al., 2003), so that its presence provides an alternative docking site and relieves dependence on Med12.

It had also been shown previously that Sox 10 cooperates with Oct6 on the MSE to activate Krox20 expression (Ghislain and Charnay, 2006; Reiprich et al., 2010). The presence of Med12specific shRNA during transfection also decreased the level of synergistic activation (Fig. 8J), suggesting that the presence of Oct6 could not compensate for the reduced ability of Sox10 to interact with the Med12 subunit.

Sox10-dependent activation of the MSE-containing luciferase reporter was also sensitive to shRNAs directed against Cdk8, Med1, or Med4 (Fig. $8 \mathrm{~K}$ ). All of these shRNAs were prevalidated for their ability to reduce the respective mediator subunits in S16 cells (data not shown). These results further support the notion that the whole Mediator complex is recruited by Sox10 to the MSE via its interaction with Med12.

A slightly earlier target for Sox10 in Schwann cells is the Oct6 gene (Jagalur et al., 2011). Therefore, we also studied the impact of Med12 on the Sox10-dependent activation of the Oct6 gene, which is mediated by SCE through its HR1 $a$ and $H R 2 b$ elements (Jagalur et al., 2011). Upon cotransfection in S16 cells, Sox10 stimulated luciferase reporter genes under control of the HR1a and the $H R 2 b$ elements (Fig. $8 L, M$ ); however, activation was refractory to the presence of Med12-specific shRNA. This is consistent with the normal Oct6 expression in Schwann cells of Med $12^{\Delta \mathrm{CNP} 1}$ mice and indicates that Sox 10 target genes do not all rely to the same extent on Med12 for their activation.

\section{Discussion}

Sox10 has been identified as an essential component of the transcriptional network that regulates the development of myelinating glia in PNS and CNS (Britsch et al., 2001; Stolt et al., 2002; Finzsch et al., 2010); this includes prominent roles in terminal differentiation and the myelination program. Furthermore, recent studies have suggested that Sox10 exerts at least part of its function through recruitment of the chromatin remodeling machinery in differentiating glia (Weider et al., 2012). Here we provide evidence that another facet of Sox10 function depends on its interaction with the Mediator complex. Our studies suggest that the interaction between Sox10 and the Mediator complex is at least in part conferred by its Med12 subunit. This was inferred from the physical interaction between Sox10 and Med12, the strong resemblance of glial defects observed in the absence of Med12 or Sox10, and the impact of Med12 downregulation on Sox10-dependent gene activation. Intriguingly, Med12 and Sox10 were both implicated by association studies in schizophrenia (Aston et al., 2005; Iwamoto et al., 2005; Philibert, 2006), further arguing for a link between these factors.

As inferred from the impact of both factors on Krox20 expression, the interaction between Sox10 and Med12 appears to have an activating effect during Schwann cell differentiation. All available data suggest that Sox10 recruits the complete Mediator complex via interaction with Med12, which as a well known coactivator facilitates preinitiation complex assembly and leads to increased transcription of Krox20 and possibly other genes that are induced during terminal differentiation. Considering the many additional effects of the Mediator complex on transcription and chromatin structure and the existence of Mediatorindependent functions of the Cdk8 module (Malik and Roeder, 2010; Borggrefe and Yue, 2011; Conaway and Conaway, 2011), additional mechanisms may well be at work.

Med12 has been shown previously to influence nervous system development (Hong et al., 2005; Rau et al., 2006; Wang et al., 2006; Rocha et al., 2010; Zhou et al., 2012). However, previous studies have focused on gross morphological aspects of nervous 

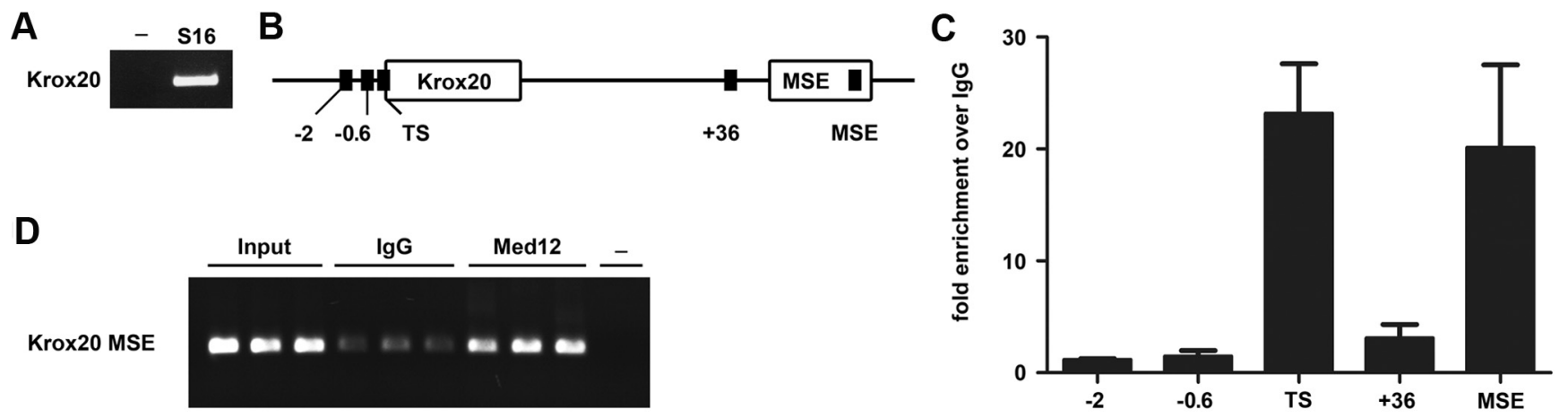

E

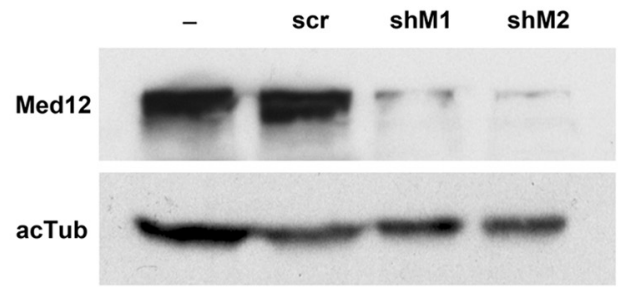

F

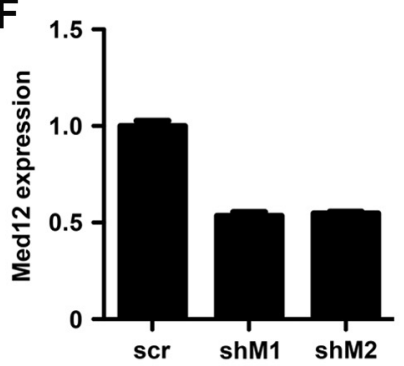

G



Krox20-MSE-luc
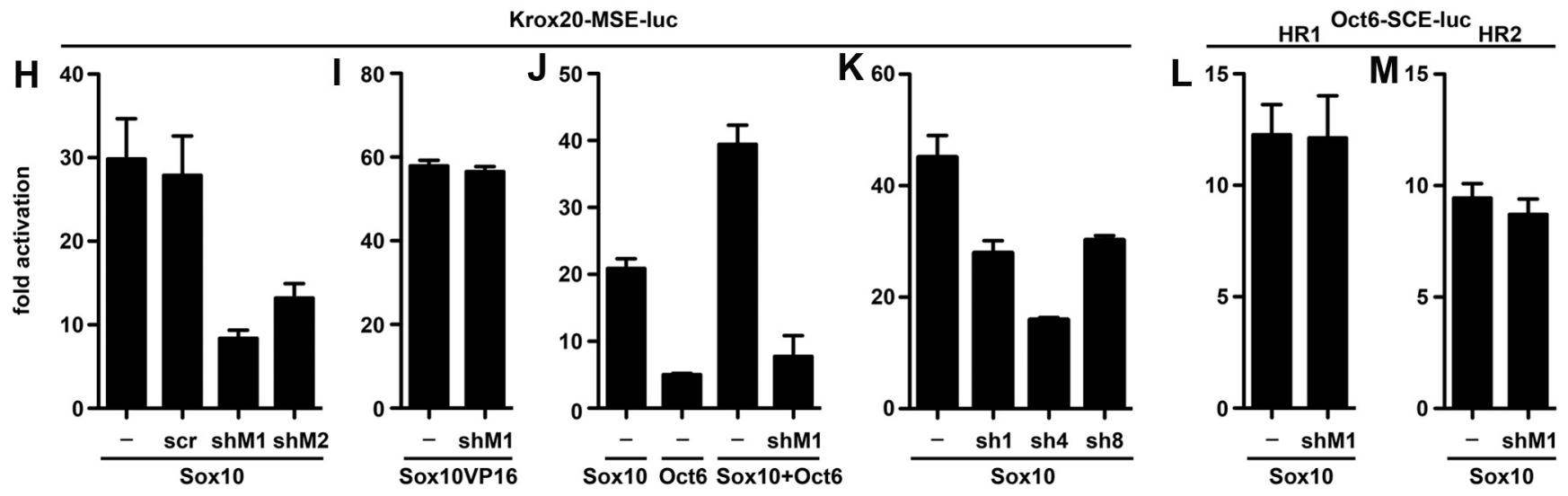

Figure 8. Sox10 and Med12 cooperate functionally in Schwann cells. A, Detection of Krox20 transcripts in S16 cells by RT-PCR and consecutive gel electrophoresis of PCR products. - indicates a water control. B-D, Chromatin immunoprecipitation was performed on chromatin prepared from S16 Schwann cells with antibodies directed against Med12 and control IgGs. qRT-PCRs were performed on immunoprecipitated chromatin to determine the relative enrichment of several regions from the Krox20 gene locus in the Med12 precipitate over the control. Experiments were performed at least three times with each PCR in triplicate. The regions probed by qRT-PCR $(-2,-0.6, \mathrm{TS},+36, \mathrm{MSE})$ and their relative location to the Krox20 gene are depicted in $\boldsymbol{B}$. The enrichment obtained for each region relative to the $\mathrm{lg} G$ control is summarized in $\boldsymbol{C}$, and $\mathbf{D}$ shows a representative chromatin immunoprecipitation experiment performed in triplicate for the Krox20 MSE with input chromatin and chromatin precipitated by control IgG or anti-Med12 antibodies. - indicates a water control. $\boldsymbol{E}$, Determination of shRNA efficiencies by Western blot with anti-Med12 antibodies using extracts from 293 cells transfected with mouse Med12 in the presence of pSuper-based expression plasmids. In addition to the empty expression plasmid, versions were used that contained Med12-specific shRNAs (shM1 and shM2) or an shRNA with scrambled sequence (scr). Acetylated tubulin (acTub) served as a loading control. $\boldsymbol{F}, \boldsymbol{G}$, Determination of shRNA efficiencies by qRT-PCR on RNA prepared from S16 cells transfected with expression plasmids for Med12-specific (shM1 and shM2) or srambled (scr) shRNAs. After normalization to $\beta$-actin, Med12 (F) and Krox20 $(\boldsymbol{G})$ expression levels in $\mathbf{S 1 6}$ cells transfected with scrambled shRNA were set to 1, and expression levels in the presence of Med12-specific shRNAs were expressed relative to it. Error bars represent the differences between two biological replicates with PCR on each sample performed in triplicate. $\boldsymbol{H}-\boldsymbol{M}$, Transient transfections were performed in S16 cells with luciferase reporters under the control of the Krox20 MSE $(\boldsymbol{H}-\boldsymbol{K})$, the HR1a $(\boldsymbol{L})$, or the HR2b $(\boldsymbol{M})$ element of the Oct6 SCE. As indicated below the lanes, expression plasmids were added to some transfections. These included expression plasmids for Sox10 $(\boldsymbol{H}, \boldsymbol{J}, \boldsymbol{K}, \boldsymbol{L}, \boldsymbol{M})$, a Sox10VP16 fusion protein $(\boldsymbol{I})$, and 0ct6 (J), as well as for shRNAs directed against Med12 (shM1 and shM2), $(\mathrm{dk} 8$ (sh8), Med1 (sh1), Med4 (sh4), or containing a scrambled version (scr). Luciferase activities in extracts from transfected cells were determined in three experiments each performed in duplicate. The luciferase activity obtained in the absence of cotransfected transcription factor plasmid, but in the presence of shRNA, was arbitrarily set to 1 and the fold inductions were calculated for all other samples relative to it. Data are


shRNA-containing transfections in $K$ according to the Student's $t$ test $(p \leq 0.001)$.

system development or specifically on the development of neurons. The present study is the first to focus on glial cells. Our deletion strategy allowed us to analyze Med12 during oligodendrocyte and Schwann cell development. In both types of myelinating glia, Med12 turned out to be required for terminal differentiation. In fact, terminal differentiation became stalled at the very onset, when central regulators of the myelination process need to be induced; these include Krox20 in Schwann cells and Nkx2.2, Gpr17, and Mrf in oligodendrocytes. The arrest therefore preceded the eventual induction of myelin gene expression.

Disturbances in myelin gene expression and developmental myelination will lead to different phenotypic manifestations depending on the severity of the defect. Abnormalities of the corpus callosum that are regularly observed in patients with Opitz- 
Kaveggia syndrome (Risheg et al., 2007) represent one such manifestation. It is thus tempting to speculate that the disease-causing Med12 mutations in Opitz-Kaveggia interfere with the role of Med12 in CNS myelination as defined in this study.

Med12 deletion in our mouse model occurred late during oligodendrocyte development. Therefore, we may have missed earlier additional functions of Med12. In contrast, deletion in Schwann cells had already taken place in the immature Schwann cell stage. Nevertheless, immature Schwann cells progressed normally into the promyelinating stage, as indicated by Sox 2 downregulation and Oct6 induction, before they became arrested at the onset of the myelinating stage. We conclude from this finding that Med12 becomes essential only during the final phases of Schwann cell development. This contrasts with the function of Sox10, which is required throughout Schwann cell development (Finzsch et al., 2010; Bremer et al., 2011; Fröb et al., 2012). Several scenarios could explain these different requirements for Med12 and Sox10. For example, it can be envisaged that Sox10 interacts directly or indirectly with different subunits of the Mediator complex and that the importance of these interactions varies in different stages of Schwann cell development. In this scenario, the Med12 interaction would become decisive only at the onset of terminal differentiation. We have shown previously that the K2 domain of Sox10 similarly gains importance when Schwann cells start to activate their differentiation program (Schreiner et al., 2007). However, despite these similarities, there is no obvious functional link between the K2 domain of Sox10 and Med12, because the $\mathrm{K} 2$ domain is not involved in the Med12 interaction and its deletion does not interfere with the ability of Sox10 to interact with Med12.

Functional redundancy between Med12 and Med12l could be another confounding factor. Considering the lack of data on Med12l, this is difficult to evaluate. The ability of Sox10 to interact with both Med12 and Med12l is compatible with such an assumption; however, the relatively low Med12l levels in Schwann cells suggest somewhat against it.

Sox10 is not the only Sox protein reported to interact with Med12. Sox2 has been proposed to interact with Med12 in embryonic stem cells, and there is evidence that Med12 modulates the function of Sox32 during endoderm development in zebrafish (Shin et al., 2008; Tutter et al., 2009). However, the most data exist for Sox9, which has been shown to physically and functionally interact with Med12 in vitro and in vivo during chondrogenesis and neural crest and inner ear development (Zhou et al., 2002; Rau et al., 2006). Furthermore, of these Sox proteins, Sox9 is the most closely related to Sox10. Considering the substantial degree of conservation between their C-terminal transactivation domains, it is not surprising that Sox10, like Sox9, interacts with Med12 via this region. It is also fairly expected that the interacting region in Med12 is the same for both proteins, even more so because the PQL domain of Med12 appears to provide the major contact surface for many different transcription-related proteins (Kim et al., 2006; Zhou et al., 2006; Ding et al., 2008). Interestingly, however, the previous study on Sox 9 focused on the transactivation domain and therefore did not detect the Dim/HMG region as a second site of contact with Med12. Considering the high degree of Dim/HMG conservation between Sox9 and Sox10, the interaction between the Dim/HMG region and Med12 likely occurs for Sox9 as well. The interaction of Med12 with TA domain and Dim/HMG region furthermore appears to occur simultaneously. Because both interactions involve the PQL domain of Med12, the TA and Dim/HMG regions must be close to each other in the three-dimensional structure of the Sox10 holopro- tein or be brought into close proximity by interaction with Med12 to create a common contact surface. It is also tempting to speculate that, under physiological conditions, the interaction between Sox10 and Med12 may only reach sufficient stability once contacts are established with both regions of Sox10.

According to a recent study, Sox9 not only interacts with Med12, but also with Med25 via Wwp2 (Nakamura et al., 2011). If conferrable to Sox10, this would support the previously mentioned assumption that Sox10 may be able to establish multiple contacts with the Mediator complex that may then be used at different times of glial development.

Finally, our data indicate that, at least in differentiating Schwann cells, Sox10 functions by recruiting both the BAF remodeling complex and the Mediator complex to the Schwanncell-specific MSE enhancer of the Krox20 gene. The relationship between these processes is currently unknown. It will be interesting to see in future studies whether chromatin remodeling is a precondition for Mediator binding or if binding of an isolated CDK8 module or Mediator complex may even be involved in chromatin remodeling. Similarly intriguing is the question of whether these complexes compete for Sox10 or could even be present at the same time. Whatever the answer, the present study provides important insights into the participation of the Mediator complex and the recruitment of the general transcription apparatus in glial differentiation and myelination.

\section{References}

Aston C, Jiang L, Sokolov BP (2005) Transcriptional profiling reveals evidence for signaling and oligodendroglial abnormalities in the temporal cortex from patients with major depressive disorder. Mol Psychiatry 10: 309-322. CrossRef Medline

Belakavadi M, Fondell JD (2010) Cyclin-dependent kinase 8 positively cooperates with Mediator to promote thyroid hormone receptordependent transcriptional activation. Mol Cell Biol 30:2437-2448. CrossRef Medline

Borggrefe T, Yue X (2011) Interactions between subunits of the Mediator complex with gene-specific transcription factors. Semin Cell Dev Biol 22:759-768. CrossRef Medline

Borggrefe T, Davis R, Erdjument-Bromage H, Tempst P, Kornberg RD (2002) A complex of the Srb8, $-9,-10$, and -11 transcriptional regulatory proteins from yeast. J Biol Chem 277:44202-44207. CrossRef Medline

Bremer M, Fröb F, Kichko T, Reeh P, Tamm ER, Suter U, Wegner M (2011) Sox10 is required for Schwann cell homeostasis and myelin maintenance in the adult peripheral nerve. Glia 59:1022-1032. CrossRef Medline

Britsch S, Goerich DE, Riethmacher D, Peirano RI, Rossner M, Nave KA, Birchmeier C, Wegner M (2001) The transcription factor Sox10 is a key regulator of peripheral glial development. Genes Dev 15:66-78. CrossRef Medline

Buchstaller J, Sommer L, Bodmer M, Hoffmann R, Suter U, Mantei N (2004) Efficient isolation and gene expression profiling of small numbers of neural crest stem cells and developing Schwann cells. J Neurosci 24:23572365. CrossRef Medline

Chen Y, Wu H, Wang S, Koito H, Li J, Ye F, Hoang J, Escobar SS, Gow A, Arnett HA, Trapp BD, Karandikar NJ, Hsieh J, Lu QR (2009) The oligodendrocyte-specific G protein-coupled receptor GPR17 is a cellintrinsic timer of myelination. Nat Neurosci 12:1398-1406. CrossRef Medline

Conaway RC, Conaway JW (2011) Function and regulation of the Mediator complex. Curr Opin Genet Dev 21:225-230. CrossRef Medline

Ding N, Zhou H, Esteve PO, Chin HG, Kim S, Xu X, Joseph SM, Friez MJ, Schwartz CE, Pradhan S, Boyer TG (2008) Mediator links epigenetic silencing of neuronal gene expression with $\mathrm{x}$-linked mental retardation. Mol Cell 31:347-359. CrossRef Medline

Donner AJ, Szostek S, Hoover JM, Espinosa JM (2007) CDK8 is a stimulusspecific positive coregulator of p53 target genes. Mol Cell 27:121-133. CrossRef Medline

Dugas JC, Tai YC, Speed TP, Ngai J, Barres BA (2006) Functional genomic analysis of oligodendrocyte differentiation. J Neurosci 26:10967-10983. CrossRef Medline 
Emery B, Agalliu D, Cahoy JD, Watkins TA, Dugas JC, Mulinyawe SB, Ibrahim A, Ligon KL, Rowitch DH, Barres BA (2009) Myelin gene regulatory factor is a critical transcriptional regulator required for CNS myelination. Cell 138:172-185. CrossRef Medline

Finzsch M, Schreiner S, Kichko T, Reeh P, Tamm ER, Bösl MR, Meijer D, Wegner M (2010) Sox10 is required for Schwann cell identity and progression beyond the immature Schwann cell stage. J Cell Biol 189:701712. CrossRef Medline

Fröb F, Bremer M, Finzsch M, Kichko T, Reeh P, Tamm ER, Charnay P, Wegner M (2012) Establishment of myelinating Schwann cells and barrier integrity between central and peripheral nervous systems depend on Sox10. Glia 60:809-816. CrossRef Medline

Ghislain J, Charnay P (2006) Control of myelination in Schwann cells: a Krox20 cis-regulatory element integrates Oct6, Brn2 and Sox 10 activities. Embo Rep 7:52-58. CrossRef Medline

Hentges KE (2011) Mediator complex proteins are required for diverse developmental processes. Semin Cell Dev Biol 22:769-775. CrossRef Medline

Hong SK, Haldin CE, Lawson ND, Weinstein BM, Dawid IB, Hukriede NA (2005) The zebrafish kohtalo/trap230 gene is required for the development of the brain, neural crest, and pronephric kidney. Proc Natl Acad Sci U S A 102:18473-18478. CrossRef Medline

Iwamoto K, Bundo M, Yamada K, Takao H, Iwayama-Shigeno Y, Yoshikawa T, Kato T (2005) DNA methylation status of SOX10 correlates with its downregulation and oligodendrocyte dysfunction in schizophrenia. J Neurosci 25:5376-5381. CrossRef Medline

Jagalur NB, Ghazvini M, Mandemakers W, Driegen S, Maas A, Jones EA, Jaegle M, Grosveld F, Svaren J, Meijer D (2011) Functional dissection of the Oct6 Schwann cell enhancer reveals an essential role for dimeric Sox 10 binding. J Neurosci 31:8585-8594. CrossRef Medline

Kim S, Xu X, Hecht A, Boyer TG (2006) Mediator is a transducer of Wnt/ beta-catenin signaling. J Biol Chem 281:14066-14075. CrossRef Medline

Knuesel MT, Meyer KD, Bernecky C, Taatjes DJ (2009a) The human CDK8 subcomplex is a molecular switch that controls Mediator coactivator function. Genes Dev 23:439-451. CrossRef Medline

Knuesel MT, Meyer KD, Donner AJ, Espinosa JM, Taatjes DJ (2009b) The human CDK8 subcomplex is a histone kinase that requires Med12 for activity and can function independently of mediator. Mol Cell Biol 29: 650-661. CrossRef Medline

Kuhlbrodt K, Herbarth B, Sock E, Hermans-Borgmeyer I, Wegner M (1998) Sox10, a novel transcriptional modulator in glial cells. J Neurosci 18:237250. Medline

Lappe-Siefke C, Goebbels S, Gravel M, Nicksch E, Lee J, Braun PE, Griffiths IR, Nave KA (2003) Disruption of Cnp1 uncouples oligodendroglial functions in axonal support and myelination. Nat Genet 33:366-374. CrossRef Medline

Li H, He Y, Richardson WD, Casaccia P (2009) Two-tier transcriptional control of oligodendrocyte differentiation. Curr Opin Neurobiol 19:479485. CrossRef Medline

Louis JC, Magal E, Muir D, Manthorpe M, Varon S (1992) CG-4, a new bipotential glial cell line from rat brain, is capable of differentiating in vitro into either mature oligodendrocytes or type- 2 astrocytes. J Neurosci Res 31:193-204. CrossRef Medline

Maka M, Stolt CC, Wegner M (2005) Identification of Sox8 as a modifier gene in a mouse model of Hirschsprung disease reveals underlying molecular defect. Dev Biol 277:155-169. CrossRef Medline

Malik S, Roeder RG (2010) The metazoan Mediator co-activator complex as an integrative hub for transcriptional regulation. Nat Rev Genet 11:761772. CrossRef Medline

Mittler G, Stühler T, Santolin L, Uhlmann T, Kremmer E, Lottspeich F, Berti L, Meisterernst M (2003) A novel docking site on Mediator is critical for activation by VP16 in mammalian cells. EMBO J 22:6494-6504. CrossRef Medline

Nakamura Y, Yamamoto K, He X, Otsuki B, Kim Y, Murao H, Soeda T, Tsumaki N, Deng JM, Zhang Z, Behringer RR, Crombrugghe Bd, Postlethwait JH, Warman ML, Nakamura T, Akiyama H (2011) Wwp2 is essential for palatogenesis mediated by the interaction between Sox9 and mediator subunit 25. Nat Commun 2:251. CrossRef Medline

Nielsen JA, Maric D, Lau P, Barker JL, Hudson LD (2006) Identification of a novel oligodendrocyte cell adhesion protein using gene expression profiling. J Neurosci 26:9881-9891. CrossRef Medline

Philibert RA (2006) A meta-analysis of the association of the HOPA12bp polymorphism and schizophrenia. Psychiatr Genet 16:73-76. CrossRef Medline

Qi Y, Cai J, Wu Y, Wu R, Lee J, Fu H, Rao M, Sussel L, Rubenstein J, Qiu M (2001) Control of oligodendrocyte differentiation by the Nkx2.2 homeodomain transcription factor. Development 128:2723-2733. Medline

Rau MJ, Fischer S, Neumann CJ (2006) Zebrafish Trap230/Med12 is required as a coactivator for Sox9-dependent neural crest, cartilage and ear development. Dev Biol 296:83-93. CrossRef Medline

Reiprich S, Kriesch J, Schreiner S, Wegner M (2010) Activation of Krox20 Gene Expression by Sox10 in Myelinating Schwann Cells. J Neurochem 112:744-754. CrossRef Medline

Renner K, Leger H, Wegner M (1994) The POU-domain protein Tst-1 and papovaviral T-antigen function synergistically to stimulate glia-specific gene expression of JC virus. Proc Natl Acad Sci U S A 91:6433-6437. CrossRef Medline

Renner K, Sock E, Bermingham JR Jr, Wegner M (1996) Expression of the gene for the POU domain transcription factor Tst-1/Oct6 is regulated by an estrogen-dependent enhancer. Nucleic Acids Res 24:4552-4557. CrossRef Medline

Richter-Landsberg C, Heinrich M (1996) OLN-93: a new permanent oligodendroglia cell line derived from primary rat brain glial cultures. J Neurosci Res 45:161-173. Medline

Risheg H, Graham JM Jr, Clark RD, Rogers RC, Opitz JM, Moeschler JB, Peiffer AP, May M, Joseph SM, Jones JR, Stevenson RE, Schwartz CE, Friez MJ (2007) A recurrent mutation in MED12 leading to R961W causes Opitz-Kaveggia syndrome. Nat Genet 39:451-453. CrossRef Medline

Rocha PP, Scholze M, Bleiss W, Schrewe H (2010) Med12 is essential for early mouse development and for canonical Wnt and Wnt/PCP signaling. Development 137:2723-2731. CrossRef Medline

Schreiner S, Cossais F, Fischer K, Scholz S, Bösl MR, Holtmann B, Sendtner M, Wegner M (2007) Hypomorphic Sox10 alleles reveal novel protein functions and unravel developmental differences in glial lineages. Development 134:3271-3281. CrossRef Medline

Shin CH, Chung WS, Hong SK, Ober EA, Verkade H, Field HA, Huisken J, Stainier DY (2008) Multiple roles for Med12 in vertebrate endoderm development. Dev Biol 317:467-479. CrossRef Medline

Stolt CC, Rehberg S, Ader M, Lommes P, Riethmacher D, Schachner M, Bartsch U, Wegner M (2002) Terminal differentiation of myelinforming oligodendrocytes depends on the transcription factor Sox10. Genes Dev 16:165-170. CrossRef Medline

Stolt CC, Lommes P, Sock E, Chaboissier MC, Schedl A, Wegner M (2003) The Sox 9 transcription factor determines glial fate choice in the developing spinal cord. Genes Dev 17:1677-1689. CrossRef Medline

Svaren J, Meijer D (2008) The molecular machinery of myelin gene transcription in Schwann cells. Glia 56:1541-1551. CrossRef Medline

Thein DC, Thalhammer JM, Hartwig AC, Crenshaw EB 3rd, Lefebvre V, Wegner M, Sock E (2010) The closely related transcription factors Sox4 and Sox11 function as survival factors during spinal cord development. J Neurochem 115:131-141. CrossRef Medline

Toda K, Small JA, Goda S, Quarles RH (1994) Biochemical and cellular properties of three immortalized Schwann cell lines expressing different levels of the myelin-associated glycoprotein. J Neurochem 63:1646-1657. CrossRef Medline

Tutter AV, Kowalski MP, Baltus GA, Iourgenko V, Labow M, Li E, Kadam S (2009) Role for Med12 in regulation of Nanog and Nanog target genes. J Biol Chem 284:3709-3718. CrossRef Medline

Wang X, Yang N, Uno E, Roeder RG, Guo S (2006) A subunit of the mediator complex regulates vertebrate neuronal development. Proc Natl Acad Sci U S A 103:17284-17289. CrossRef Medline

Wegner M, Drolet DW, Rosenfeld MG (1993) Regulation of JC virus by the POU-domain transcription factor Tst-1, Implications for Progressive Multifocal Leukoencephalopathy. Proc Natl Acad Sci U S A 90:47434747. CrossRef Medline

Weider M, Küspert M, Bischof M, Vogl MR, Hornig J, Loy K, Kosian T, Müller J, Hillgärtner S, Tamm ER, Metzger D, Wegner M (2012) Chromatin-remodeling factor Brg1 is required for Schwann cell differentiation and myelination. Dev Cell 23:193-201. CrossRef Medline

Wissmüller S, Kosian T, Wolf M, Finzsch M, Wegner M (2006) The Highmobility-group domain of Sox proteins interacts with the DNA-binding domains of many transcription factors. Nucleic Acids Res 34:1735-1744. CrossRef Medline 
Zhou H, Kim S, Ishii S, Boyer TG (2006) Mediator modulates Gli3dependent Sonic hedgehog signaling. Mol Cell Biol 26:8667-8682. CrossRef Medline

Zhou H, Spaeth JM, Kim NH, Xu X, Friez MJ, Schwartz CE, Boyer TG (2012) MED12 mutations link intellectual disability syndromes with dysregulated GLI3-dependent Sonic Hedgehog signaling. Proc Natl Acad Sci U S A. 109:19763-19768. CrossRef Medline
Zhou R, Bonneaud N, Yuan CX, de Santa Barbara P, Boizet B, Schomber T, Scherer G, Roeder RG, Poulat F, Berta P, Tibor S (2002) SOX9 interacts with a component of the human thyroid hormone receptor-associated protein complex. Nucleic Acids Res 30:3245-3252. CrossRef Medline 